\title{
Gender in the Journals: Publication Patterns in Political Science
}

Dawn Langan Teele, University of Pennsylvania

Kathleen Thelen, Massachusetts Institute of Technology

ABSTRACT This article explores publication patterns across 10 prominent political science journals, documenting a significant gender gap in publication rates for men and women. We present three broad findings. First, we find no evidence that the low percentage of female authors simply mirrors an overall low share of women in the profession. Instead, we find continued underrepresentation of women in many of the discipline's top journals. Second, we find that women are not benefiting equally in a broad trend across the discipline toward coauthorship. Most published collaborative research in these journals emerges from all-male teams. Third, it appears that the methodological proclivities of the top journals do not fully reflect the kind of work that female scholars are more likely than men to publish in these journals. The underrepresentation of qualitative work in many journals is associated as well with an underrepresentation of female authors.

\section{INTRODUCTION}

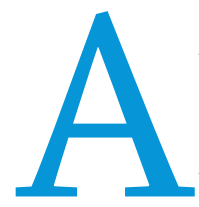

dvancement up the academic career ladder is so heavily tied to evidence of research output that even outside of the rarified halls of academe the expression "publish or perish" is well known. Today, publication is more important than ever: placing one's work in top-tier journals is important not just to tenure and promotion decisions but also plays a role in the job market for many entry-level positions. This article explores publication patterns across ten prominent political science journals, documenting a significant gender gap in publication rates for men and women.

Our study takes place in the context of renewed interest in the role of women in the profession. Although women have made great strides over the past several decades, they still face important obstacles even beyond the obvious and longstanding challenges many of them confront in reconciling career and family. Research across a range of different disciplines has uncovered subtle, and sometimes not-so-subtle biases against women in teaching evaluations (MacNell, Driscoll, and Hunt 2014), letters of recommendation (e.g., Trix and Psenka 2003), peer review (Wennerås and Wold 1997), and deliberation and group interactions (Karpowitz and

Dawn Langan Teele is an assistant professor of political science at the University of Pennsylvania. She can be reached at teele.academic@gmail.com.

Kathleen Thelen is the Ford professor of political science at the Massachusetts Institute of Technology. She can be reached at kthelen@mit.edu.
Mendelberg 2014), among many others. ${ }^{1}$ Recent research focusing specifically on political science has also uncovered important gender effects. For example, Maliniak et al. (2013) identified a significant gender citation gap in the field of international relations. ${ }^{2}$ Ongoing work by Karen Alter and colleagues analyzes the gendered construction of status, examining the underrepresentation of women both on popular platforms (such as Wikipedia) and in professional associations associated with high prestige (e.g., the American Academy of Arts \& Sciences). 3 The American Political Science Association's (APSA) Committee on the Status of Women in the Profession has initiated a project to track the advancement of women through the academic pipeline-collecting data from the largest $\mathrm{PhD}$-granting institutions in political science in an attempt to identify where the leaks are occurring. 4

This study is part of these larger efforts. In it, we seek to shine a light on one area-scholarly publications-that we know to be enormously important to tenure and advancement in the profession. It is hard to overstate the importance of publication in top-tier journals in determining who advances-and who fails to advance-within our discipline. Scholarly productivity is regularly measured by number of publications, often alongside associated citation counts. Moreover, quantity aside, assessments of the quality of a scholar's output are powerfully shaped by the relative prestige associated with particular journals. What constitutes "high quality" research in political science is socially and politically constructed. Journals and journal editors play a central 
role in that process because, to a very large extent, publication in the discipline's premier outlets is itself equated with "research of the highest quality."

We are not the first to inquire into gendered patterns of publication in our field. 5 A 1995 study by Cheryl Young examined publication rates for women across 15 political science journals between 1983 and 1994 (Young 1995). At the time, women made up approximately one quarter of the total membership in the APSA, after doubling over the previous decade $(1995,525)$. Against this backdrop, Young's finding that about $24 \%$ of the nearly 6,00o articles in her sample included at least one female author seemed very promising. Still, as she noted, it was hard to overlook the fact that this figure lagged significantly behind the share of articles in her sample that had at least one male author $(85 \%) .{ }^{6}$ Also striking in her results was that the work of female scholars was far more likely to appear in the less prestigious journals in her sample the kinds of research teams whose work increasingly populates the pages of many journals. Third, it appears that the methodological orientation of many of the top journals does not fully reflect the kind of work that female scholars are more likely than men to publish in such journals. The dearth of qualitative work in many journals may exacerbate the exclusion of women.

We begin by introducing the dataset, and then turn to an analysis of the patterns we observe.

\section{DATASET ON GENDER IN THE JOURNALS}

Our research focuses on ten journals that are widely accepted as leading forums for high-quality political science research in the United States, including the APSA's own two flagship journals, the American Political Science Review (APSR) and Perspectives on Politics (POP). The other eight journals in our sample are: the American Journal of Political Science (AJPS), Comparative Politics (CP),

\section{Yet, even as their presence among PhD graduates and university faculties has grown, women continue to be underrepresented among authors in the journals that are typically seen as the discipline's most prestigious outlets.}

than in the top national journals (e.g., the APSR). Young optimistically reasoned that this was a function of the relatively recent arrival of women into the profession. She speculated that women in the "lower academic tiers may be targeting lower status journals because they are still learning their craft and may be hesitant to submit their work to the top ranking journal" $(1995,526)$, and she predicted that as women advanced to the "upper tiers of academe" their work would appear more regularly in the top journals as well.

Two decades later, our research shows that these optimistic projections have failed to materialize. Women are no longer a small minority and they are no longer newcomers learning this craft. For over a decade now, women have accounted for approximately $40 \%$ of all new $\mathrm{PhDs}$ in political science, according to the NSF survey of earned doctorates. 7 Women also now make up $40 \%$ of graduate student members of the APSA, and a large and growing share of members in early stages of their careers (39\% of assistant professors and $33 \%$ of associate professors). Yet, even as their presence among $\mathrm{PhD}$ graduates and university faculties has grown, women continue to be underrepresented among authors in the journals that are typically seen as the discipline's most prestigious outlets. Among those whose work was published in the $A J P S$, for example, less than $20 \%$ were women. Given the importance of publication to tenure, promotion, and salary decisions, the gender gap in journals such as AJPS has enormous implications for women's advancement in political science.

Our analyses reveal three trends that form part of a gender gap in publication. First, we find that even as the share of political scientists who are women has grown, there continues to be a pronounced underrepresentation of women in the pages of many of the top journals in political science. This suggests that the low percentage of female authors is not merely a reflection of women's numbers in the profession. Second, we find evidence that women are not participating equally in a broad move across the discipline toward coauthorship. We see signs instead of gendered patterns of exclusion from
Comparative Political Studies (CPS), International Organization (IO), Journal of Conflict Research (JCR), Journal of Politics (JOP), Political Theory (PT), and World Politics (WP). We sought to include the "top ranked" journals, though as Giles and Garand (2007) have noted, there is a wide range of ranking schemes, and different approaches produce somewhat different rankings. We settled on a sample of journals that show up regularly, despite differences in ranking criteria, thus reflecting some consensus in the discipline. However, we also sought to include at least one journal from each of the main recognized subfields in political science, as well as journals associated with different methodological leanings. ${ }^{8}$

Our data collection efforts began by acquiring the meta-data on all articles published in these 10 journals from 2000 to 2015 . Web-scraping techniques allowed us to gather information on nearly 8,ooo articles $(7,915)$, including approximately 6,ooo research articles $(5,970)$. The journals vary in terms of the level of information they provide about the nature of each article, but we were generally able to determine the type of article (whether a research article, book review, or symposium contribution), the names of all authors-from which we could calculate the number of authors-and often the institutional rank of each author (for example, assistant professor, full professor, etc.). In what follows, we describe the variable generation process for all types of articles in the dataset, but note that the findings we report stem from an analysis of authorship for research articles only, and not reviews or symposia.

Using an intelligent guessing technique (compared against a hand-coding method) we used authors' first names to code author gender for all articles in the database. We also hand-coded the dominant research method employed by each research article. ${ }^{9} \mathrm{We}$ were further able to generate women among authors (\%) which is the share of women among all authors published in each journal, as well as other variables related to the gender composition for each article, which include information about whether each article was written by a man working alone, a woman working alone, an all-male team, an all-female team, or a co-ed team of authors. 
Table 1

Database of Gender in the Journals Overview

\begin{tabular}{|c|c|c|c|c|c|}
\hline & Sample Starts & Sample Ends & \# Research Articles & Rank Available? & Percent of Authors who are Women (2000-2015) \\
\hline AJPS & 2000 & 2015 & 909 & Yes & 18.02 \\
\hline APSR & 2000 & 2015 & 634 & No & 23.43 \\
\hline $\mathrm{CP}$ & 2000 & 2015 & 318 & Yes & 31.46 \\
\hline CPS & 1999 & 2015 & 823 & No & 32.17 \\
\hline 10 & 2000 & 2015 & 349 & Yes & 23.64 \\
\hline JCR & 2000 & 2015 & 372 & Some & 23.60 \\
\hline JOP & 2000 & 2015 & 1053 & Yes & 22.91 \\
\hline POP & 2003 & 2015 & 611 & Yes & 33.55 \\
\hline PT & 1999 & 2015 & 629 & No & 33.74 \\
\hline WP & 2000 & 2015 & 250 & Yes & 24.41 \\
\hline
\end{tabular}

Because the convention in political science is generally to display author names alphabetically, we have not coded categories like "first author" or "last author" which are important in the natural sciences.

An accurate assessment of an author's gender is critically important for the validity of our analysis. Given the large number of articles in the sample and the high levels of coauthorship, we automated the process of assigning a gender to authors. In practice, we are "imputing" gender, because we do not know about authors' gender identity.10 This process involved four steps. First, we employed research assistants to hand-code the gender of each author for 1,311 articles. Second, using Python scripts, we used authors' first names to query a database of names drawn from user profiles of major online social networks to guess the likely gender of all authors. ${ }^{11}$ Along with assigning genders to first names, the guessing algorithm provided a certainty measure from o to 1 that recorded its confidence in the guess. Third, we compared the hand-coded genders with the guessed values to evaluate the accuracy of the technique. Fourth, we fixed discrepancies and conducted web searches for any author for which the algorithm produced a certainty score of less than 1 .

To assess the accuracy of the gender-guessing algorithm we compared the 32 cases where the computer-generated guess did not match our RA's hand coding in the 1,311 articles coded by both methods ( $2 \%$ ). The algorithm was incorrect in 26 cases ( $2 \%$ ), almost always incorrectly guessing that a scholar was a woman (23 out of 26). In the six cases where the hand coding was incorrect, the RAs over-guessed men. Note that of all the cases where the RAs were incorrect, the algorithm had a very high certainty score of 1. In cases where the algorithm was incorrect, the average certainty score was o.8. Along with fixing the gender assignment of all of the authors revealed by the comparison, we had a second RA re-check the assignment for all authors whose certainty score was less than 1. The RA found an additional 92 mistakes in the 5,510 articles where gender was only assigned by the algorithm (1.7\%), and these were all fixed. Note that repeat incorrect guesses for the same author were very common, so we are confident that we have eliminated most of the incorrect assignments. Note, too, that because the algorithm tended to over-guess women, this would inflate the presence of women among authors and not undermine our findings.

Table 1 gives an overview of the sample, and also reports the share of women as a total of all authors in the sample period for each journal. Figure 1 provides a first look at the share of male and female authors for each journal over the full time period. The sections to follow consider a series of possible explanations for the patterns we observe here.

\section{Is it the Pool?}

As a first step, we sought to develop an overview of the share of women in the profession. This is, of course, a moving target because, while some attrition is to be expected among both men and women, research has shown that the career pipeline in academia is especially leaky for women (e.g., APSA 2005). We establish three benchmarks that can serve to orient the discussion-the share of female $\mathrm{PhDs}$ in political science, the share of female members belonging to the APSA, and the share of women among tenure ladder faculty in the 20 largest PhD-granting institutions.

Earning a $\mathrm{PhD}$ is the crucial first step toward a career as a political scientist. Thus, we begin with the female share of all political

\section{Figure 1}

Women and Men as a Share of All Authors of Research Articles in 10 Political Science Journals, 2000-2015

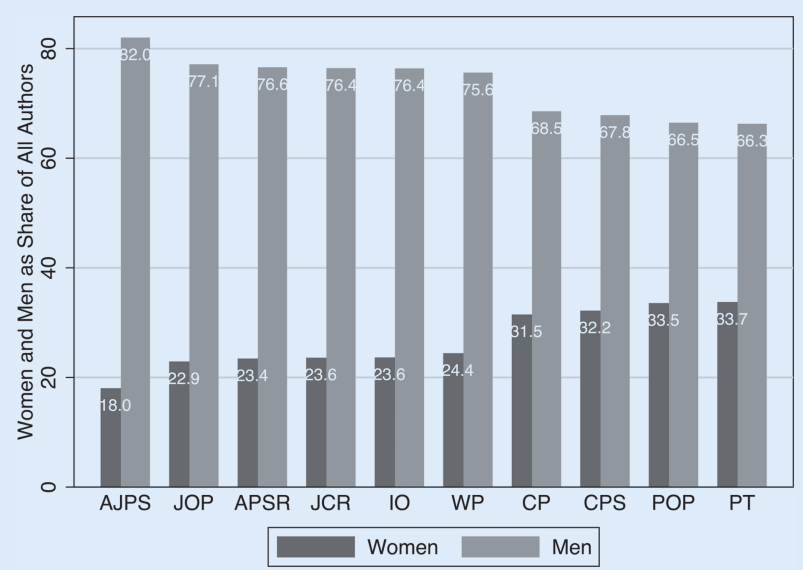

Note: Over the entire time period, the share of women among all authors was highest for Perspectives on Politics and Political Theory (nearly 34\%) and lowest for the AJPS (18\%) and the JOP (23\%). 
science PhDs, which over the past decade has been steady and rather high, at around $40 \%$ (NSF survey of earned doctorates). As noted earlier, an alternative measure-also based on NSF datathat combines earned doctorates in political science and public administration records an even higher share $(47.1 \%$ in 2008$)$. However, we use the more conservative figure in what follows.

We do not have reliable data on the share of women who, after having earned a $\mathrm{PhD}$, then go on to a career in political science in the academy. The best surrogate measure we have available is the share of all members of the APSA who are women. The aggregate figure is higher at these lower ranks-which, of course, is precisely the group whose advancement depends on demonstrating scholarly productivity-in all that follows, we will refer to the more conservative (overall) share of women for each of the three benchmarks.

How well represented are these women in the pages of the top journals? Are female scholars published in these journals in approximately the same proportion as their presence in the discipline? In PhD-granting institutions? In the top-ranked departments? ${ }^{13}$ The answer to almost all of these questions is

\section{Are female scholars published in these journals in approximately the same proportion as their presence in the discipline? In PhD-granting institutions? In the top-ranked departments? The answer to almost all of these questions is "no" for most of the journals in our sample, as figure 3 illustrates.}

(31\% in 2014) is lower than the share of women who earned a doctorate in that year. However, the corresponding APSA membership figures for women earlier on in their careers (at the lower ranks of the tenure track) are significantly higher, and essentially the same as the $\mathrm{PhD}$ share for assistant professors (nearly 40\%), dropping somewhat for associate professors (33\%). Figure 2 provides a breakdown of APSA membership by gender and rank.

We know from previous research (e.g., APSA 2005, 4) that women are relatively more likely than men to wind up in permanent lectureships or at teaching institutions and liberal arts colleges. Hence, a third benchmark is the share of women in the discipline's largest PhD-granting departments. ${ }^{12}$ Here, we find that overall, $27 \%$ of ladder faculty are female (as of 2015). However, once again, the share of women rises amongst the younger cohorts: women make up $38 \%$ of untenured ladder faculty at such institutions.

We note that even though the share of women (both within the APSA and within the largest PhD-granting departments)

\section{Figure 2}

\section{APSA Membership by Gender and Academic Rank}

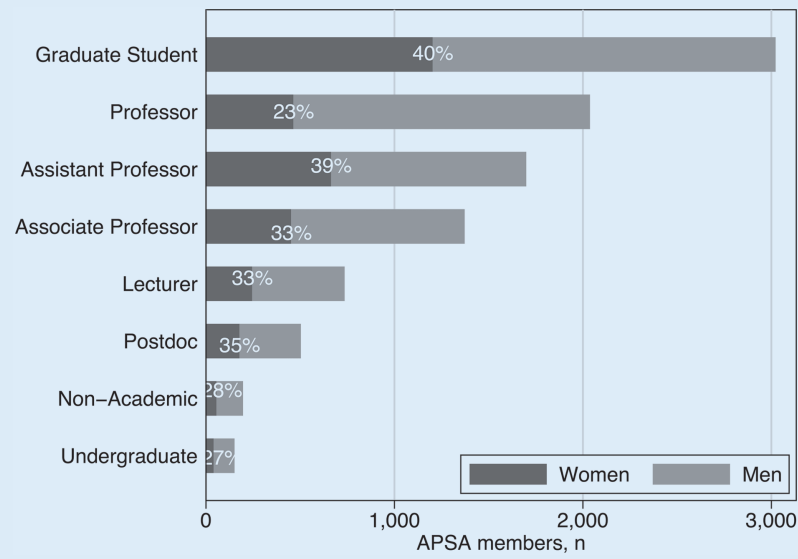

Source: APSA "no" for most of the journals in our sample, as figure 3 illustrates.

Figure 3 plots the share of all authors contributing to research articles (as opposed to review essays) who are women. Journals higher up on the plot have a higher proportion of women among authors-for example $33.5 \%$ of authors in Perspectives on Politics are women-while journals lower down have a lower share of women among their authors; only $18 \%$ of authors in the AJPS over this period are women (similar to the APSR, with 23.4\%). The figure also includes three lines-line A depicts the proportion of women among tenure-ladder faculty at the largest $20 \mathrm{PhD}$-granting departments in 2015 (27\%); line B shows the share of women among all APSA members in 2015 (31\%); line C charts the share of women among newly conferred doctorates $(40 \%)$. What is striking is that, compared against these benchmarks, only four journalsPerspectives on Politics, Political Theory, Comparative Politics, and

\section{Figure 3}

Women as Share of All Authors in 10 Political Science Journals, 2000-2015

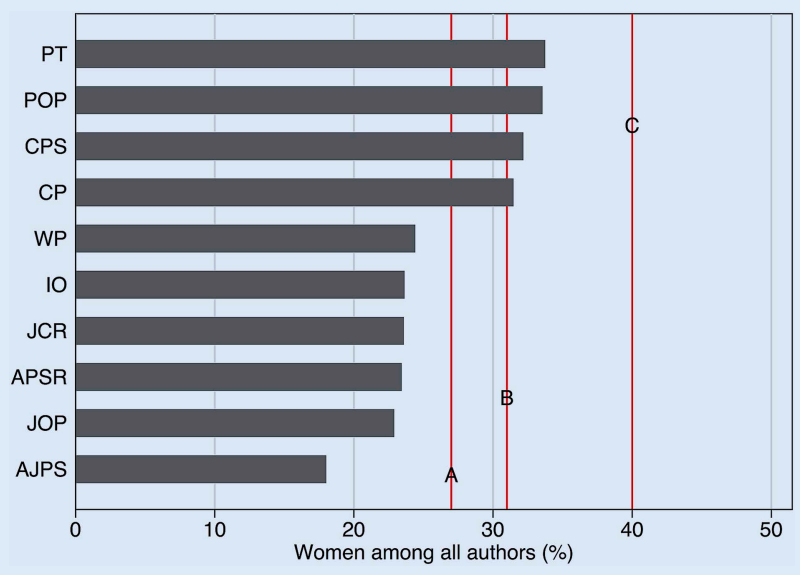

Note: Line A represents the share of women in the ladder faculty at the largest $20 \mathrm{PhD}$-granting departments in the discipline (27\%). Line B represents the share of women among all APSA members (31\%). Line C represents the share of women among all newly minted PhDs as reported in the NSF's survey of earned doctorates. 
Comparative Political Studies-are publishing women at rates consistent with women's presence in the discipline as a whole.

This mix of journals suggests a hypothesis that we are not able to fully test with the data available to us. It could be that publication rates across these journals reflect differences in the composition of scholars working within specific subfields. For example, we know that women have traditionally been underrepresented among scholars in American politics and international relations, and better represented among students of comparative politics (Shames and Wise 2017, figure 2). This could explain the fact that those journals in our sample that explicitly focus on comparative politics (CP, CPS ) publish, on average, more female authors than those with a significant international relations emphasis $(I O, J C R, W P)$.

However, gendered sorting into subfields would not explain is the pattern we observe for the four "generalist" journals in our sample (AJPS, APSR, JOP and POP). These four journals-official journals either of the national association or one of its regional affiliates-are all "generalist" outlets, in that their websites indicate that they are open to submissions across all subfields. ${ }^{14}$ Yet, as figure 3 shows, women are underrepresented, against all three benchmarks, in three of those four "generalist" journals.

Returning to the full sample, we can use the APSA's figures on the share of women at different academic ranks (e.g., graduate students, post-doctorates, assistant, associate, and full professors) to examine the gender publication gap at each rank. In figure 4 equal representation would imply clustering along the 45 -degree line. Instead, we see a significant gender gap for female authors at nearly every professional rank. For example, although about $23 \%$ of full professors are women, only $11 \%$ of the full professors who write for these top journals are women, meaning that there is a gender gap of 12 points at the full professor level. Thirty-nine percent of assistant professors are women, but women make up only $27 \%$ of assistant professor authors in the journals, again a gap of 12 points. In terms of the academic career ladder, the gap for female assistant professors is especially consequential, as this is the group most needing publications to advance to tenure.

\section{Figure 4 \\ Representation of Women in the Journals by Academic Rank}

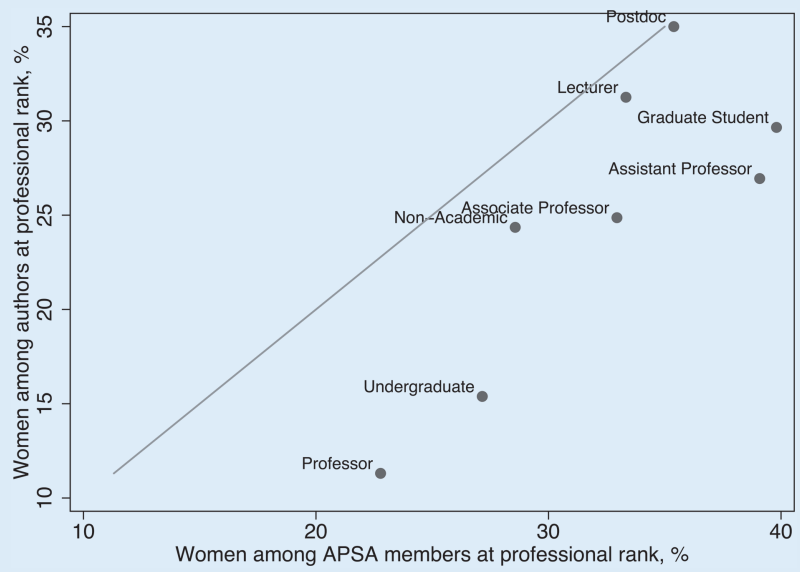

Note: The share of women at a given ladder level is on the $x$-axis, while their representation among authors at that rank in the top journals is along the $y$-axis. Equal representation would mean that the points fall along the 45-degree line.
Summing up the results with respect to our first question (women as a share of the pool of all authors), we find that publication rates at all of the journals in our sample are well below the share of female PhDs. More significantly, with the notable exceptions of Perspectives on Politics, Political Theory, Comparative Politics and Comparative Political Studies, they are also below the share of women in the APSA. Many of these journals are, in fact, also publishing a smaller share of female authors than the share of women on the faculty of the 20 largest PhD-granting departments. Strikingly large gender gaps exist at almost every academic rank. Relative to their share among full professors, for example, women publish in the top journals at far lower rates. Most consequentially of all, female assistant professors seem to be quite disadvantaged relative to their male peers when it comes to placing their work in the top journals.

\section{Coauthorship}

Additional factors that could play a role in the gender gap in publication patterns include changing norms and practices with respect to coauthorship. A 2005 APSA report on "Advancement of Women in Academic Political Science in the United States" emphasized the importance of inclusion in collaborative research and publication networks (2005, 2, 12 and passim). We know from previous research (e.g., Fisher et al. 1998) that coauthorship and scholarship by research teams has been growing in the discipline. Yet, we find evidence that women are not benefiting equally in the resulting multi-authored publications in the field's top journals (see also Evans and Moulder 2011).

Previous research on coauthorship by Fisher et al. (1998) focused on three journals (APSR, AJPS, and JOP) over the period from 1950 to 1996 . The authors document an increase in multi-authored articles over this period, and show that by the mid-1990s almost half the articles that appeared in these three journals were co- or multi-authored. The context in which Fisher et al.'s study took place was one in which the discipline was just beginning to grapple with the issue of how to evaluate multi-authored work, and so the core question motivating their research was whether articles authored by women were more or less likely to be collaborative across the sexes than articles authored by men. The answer to this was a resounding yes: women were nearly four times more likely to publish articles coauthored with men than the other way around (1998, 852). For Fisher et al., the worry was that if multi-authored work were underrated, women would not benefit much from their apparently greater proclivity to collaborate with others, raising the "issue of how multi-authored articles should be evaluated" $(1998,854)$. We return to the issue of how women's contribution to collaborative research is evaluated below.

Our core concern at this point, however, is a somewhat different one, namely whether women have the same opportunities as men to engage in collaborative research and publication as reflected in overall publication patterns. Viewed in this light, Fisher et al.'s data reveal a different pattern. Their figures suggest that the decline in single-authored work from the 1950 s to the 1990 s was largely made up by an increase in all-male collaborations. Articles published by exclusively male multi-author groups rose as a percentage of all articles published across all three journals to $39.2 \%$, while cross-gender collaborations rose but only to $13 \cdot 5 \%$. 
Figure 5

Average Number of Authors, Per Article, by Journal
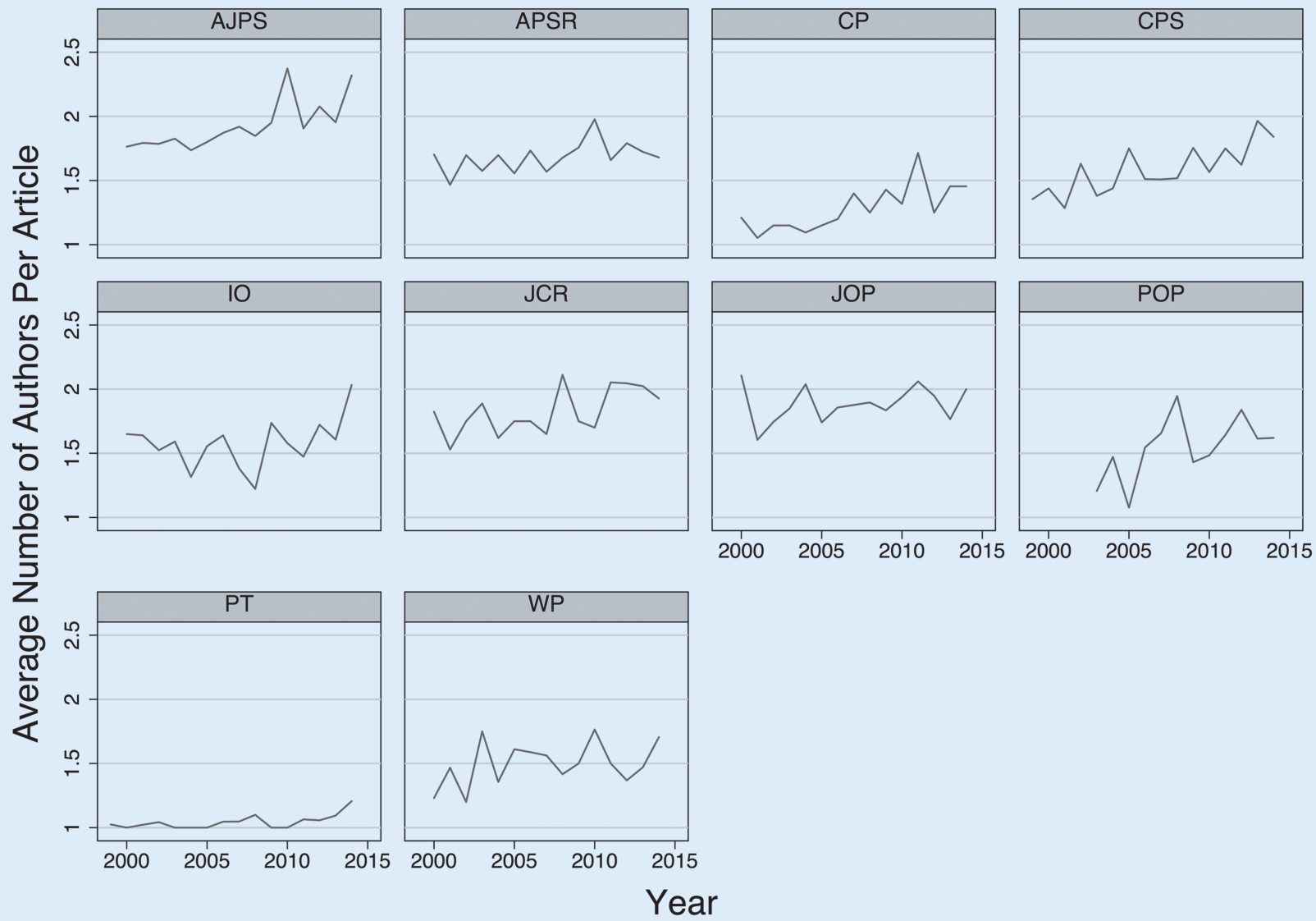

Note: The appendix provides some data on long-term trends from the 1950s (from Fisher et al. 1998).

Our data allow us to extend Fisher et al.'s observations to 2015, and for a wider range of journals. As figure 5 shows, we observe a continued increase in coauthorship in most of the journals. For the AJPS, the share of coauthored articles grew by 15 percentage points, to $66.1 \%$, by 2015 ; for the APSR it grew almost 9 percentage points, to $54.2 \%$; for the JOP it grew by 12.6 percentage points, to $63.9 \%$.

Digging a little deeper, we investigate gender in the pattern of coauthorship for our full sample of journals. Figure 6 displays the results. The most common form of publication across all the journals is a single male author (41.1\%), while the second most common form of publication is an all-male "team" of more than one author (24\%). Women working alone represent $17.1 \%$ of publications, while all-female teams represent just $2.4 \%$ of all journal articles. Finally, cross-gender collaborations account for $15.4 \%$ of publications. ${ }^{15}$

The patterns of coauthorship have changed over time, but not unequivocally in a direction that is beneficial for women. Figure 7 shows that solo male authorship has declined over the last 15 years, but is still the most common form of publication in these journals. In 2000, solo male articles or all-male teams accounted for $71.4 \%$ of all articles, while in 2014 this combination accounted for $56.9 \%$. In the meantime, cross-gender collaboration rose from $13.2 \%$ of all articles in 2000 to $24.5 \%$ in 2014 . But female solo authorship has been relatively flat over this period, well under $20 \%$, and all-women teams remain rare, at $2 \%$ in 2000 and $3.4 \%$ in 2014 . Thus, the main growth of female authorship in the top journals is through their collaboration with men.

\section{Figure 6 \\ Gendered Patterns of Authorship for All Journals}

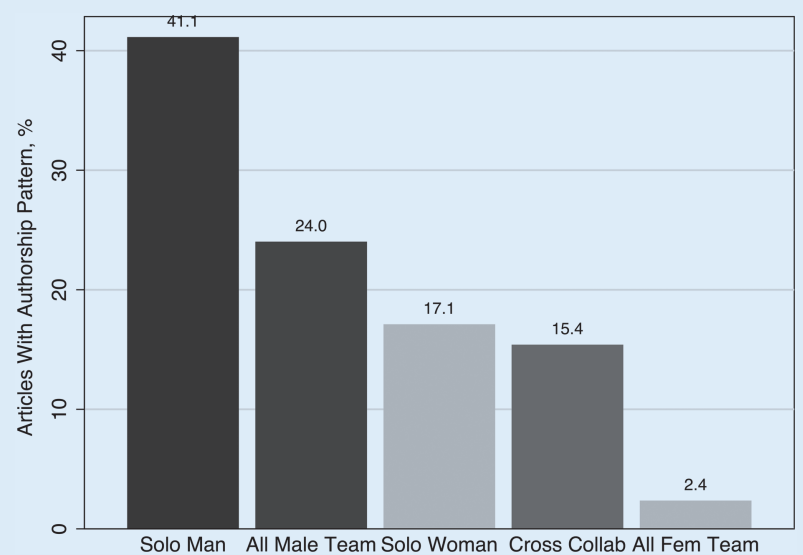

Note: The columns report the share of all articles in our sample that reflect particular authorship patterns: the first column is of men publishing alone, followed by all male teams, women alone, cross-sex collaboration, and finally, all female teams. 
There are certainly differences across journals in the importance of coauthorship and the prevalence of collaboration. Figure 8 shows that the AJPS is slightly more likely to have articles authored by all-male teams than by men working alone, and is very unlikely to publish an article authored by only one woman (6.8\%). Other
One possible explanation for these patterns is that women are less likely to be invited to collaborate in these collective research and publication projects, which, if true, would then exacerbate the gender gap in publication. Our data do not allow us to examine the formation of research teams. What we can

\section{In the meantime, cross-gender collaboration rose from $13.2 \%$ of all articles in 2000 to $24.5 \%$ in 2014. But female solo authorship has been relatively flat over this period, well under $20 \%$, and all-women teams remain rare, at $2 \%$ in 2000 and $3.4 \%$ in 2014.}

journals, like JCR and JOP, exhibit a similar pattern, publishing more work by all-male teams than any other type, and very few articles $(<10 \%)$ by women working alone.

Table 2 presents more data on patterns of collaboration for each of the journals, providing an even more granular picture and documenting significant variation across the journals for the entire time period of the study. For example, over $70 \%$ of all articles published in the AJPS and the APSR are authored exclusively by men (column 3), working either alone or in collaboration with other men (column 5$) \cdot{ }^{16}$

The underrepresentation of women in multi-authored work appears not to be function of their unwillingness to engage in collaboration. In table 2 , column 7 shows that on average, $51 \%$ of publications with at least one female author emerge from collaborative work, while column 10 shows that $47.4 \%$ of publications with at least one male author are team projects. But while most of the work with at least one male author emerges from all-male teams (column 12, $28.8 \%$ ), only $6.6 \%$ of the publications with at least one female author are all-female teams. Focusing on crosssex collaborations specifically, we see that women publishing in these journals are much more likely than men to engage in such endeavors. Column 9 of table 2 shows that $44.8 \%$ of articles with at least one female author emerge from cross-sex collaboration, while only $18.6 \%$ of articles with one male author emerge from cross-gender teams (column 13). This finding mirrors what Fisher et al. found in 1998 .

\section{Figure 7}

Gendered Patterns of Authorship Across Journals, over Time

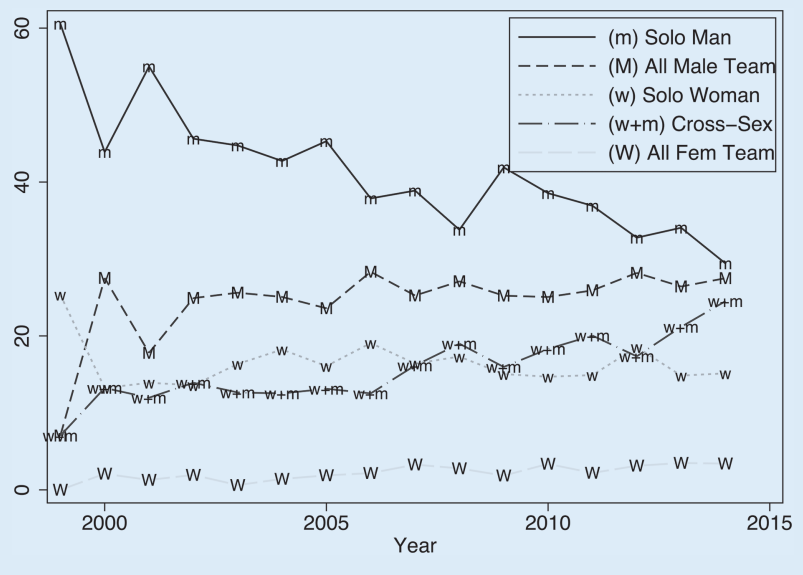

surely say, however, is that as long as coauthorship continues to rise in the top political science journals, the gender disparities in these research teams put women who come up for tenure or promotion at a distinct disadvantage.

At the same time, and indeed as Fisher et al. noted back in 1998 , for collaborative efforts to work for women, the evaluation of such work needs to be gender-neutral. In particular, Fisher et al. noted the possibility that women's greater proclivity to collaborate would not redound to their advantage "if women's contributions are implicitly attributed to male coauthors" (1998, 854). A recent study in economics has shown that the contributions of women to multi-authored work in that field are indeed often discounted. Specifically, the study shows that women have a lower probability of getting tenure than men if most of their articles are coauthored (Sarsons 2015). In short, the trend toward coauthorship will benefit female scholars only if women are included in these research teams, and if they then also get credit for their apparently greater tendency to collaborate across gender lines.

Summing up our results with respect to authorship patterns, we find that the most common form of authorship over the past 15 years has been-and continues to be-men working alone. This is true even though the average number of authors per article has risen across many of the journals in our sample. For collaborative research, despite an increase in cross-gender collaboration, all-male teams remain predominant, and all-female teams continue to be extremely rare. The number of articles published by female authors working alone has been mostly constant, which means that the (relatively small) overall increase in the share of female authors comes from coauthorship with men. We have also identified some of the dilemmas posed by coauthorship. However, for now what is certainly true-and highly consequentialis that there are multiplier effects for coauthored work in recruitment, tenure, and promotion processes. Every author on a coauthored piece can list the publication that his or her team has produced, and so patterns of inclusion/exclusion-for whatever reason-from these research teams can significantly affect one's perceived productivity. At the same time, however, if the contribution of female authors is discounted (as appears to be the case in Sarsons's research), then when it comes to coauthorship, women may be damned if they don't, but also damned if they do.

\section{METHODOLOGICAL APPROACH}

Finally, we consider the possibility that the gendered publication patterns that emerge from our data reflect a disconnect between the methodological leanings of different journals and the types of work that female scholars are more likely than their male 
Figure 8

Coauthorship Patterns Within Journals
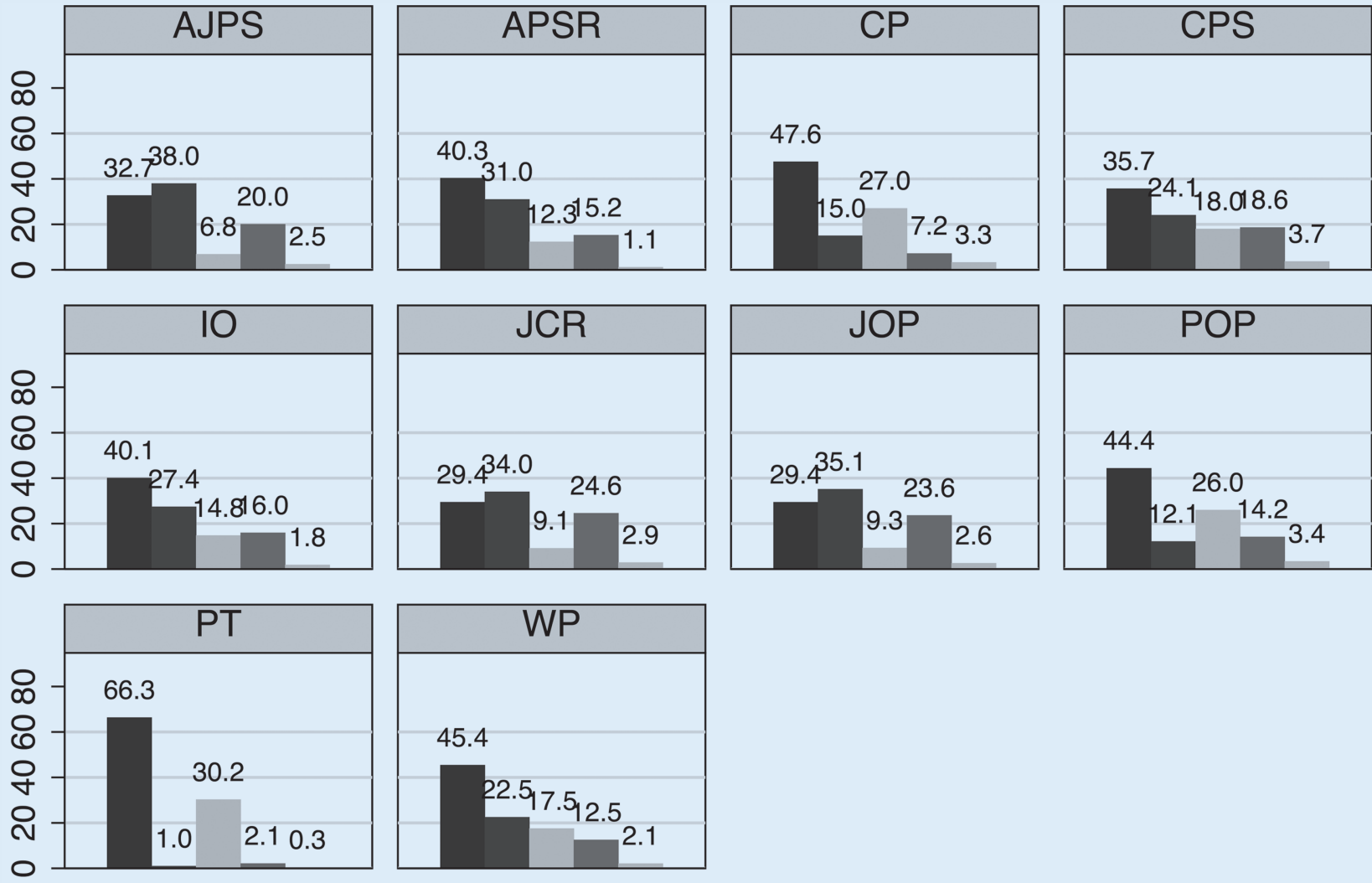

Solo Man

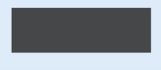

All Male Team

Solo Woman

Cross Collab

All Fem Teap

colleagues to produce and to publish. The "Perestroika" movement of a few decades ago was motivated by the sense that many of the discipline's top journals were privileging particular kinds of work based on specific (mostly quantitative) methods. ${ }^{17}$ The question here is somewhat different, namely whether the methodological leanings of particular journals provide de facto barriers to women having their work published.

Several previous studies point to this possibility. For example, based on an analysis of articles published in eight prominent political science journals between 1995 and 2004, Breuning and Sanders (2007) find that female authors are more prevalent in journals publishing a larger share of case-study work. Conversely, they observe that "journals with higher proportions of statistical analyses...are less likely to publish work by women" (2007, 349)..$^{18}$ More recently, Evans and Moulder examine publication patterns in a smaller set of journals (APSR, AJPS, JOP and PS) and find a similar pattern. Their data show that "articles written by female lead authors were significantly more likely to be qualitative...than were articles written by male lead authors" $(2011,796) .{ }^{19}$

To examine the relationship between gender and method, we coded our sample using categories that broadly conform to the categories that the APSR uses in its reports to the Association. ${ }^{20}$ Specifically, we examine whether an article's primary evidentiary base draws from one of the following traditions: qualitative investigation, formal theory, traditional statistical analyses, experimental methods, conceptual exploration, or political theory.

What we find resonates with the results in Breuning and Sanders (2007). Figure 9 classifies articles for all journals except Political Theory by whether the primary methodology was conceptual, experimental, formal theory, political theory, qualitative, or statistical. Examining the publication patterns across diverse methods, we find that women are underrepresented in work across all methods except qualitative work and political theory. The gap is most severe in work that relies primarily on formal theory, followed by conceptual and experimental work. By contrast, among articles categorized as employing primarily "qualitative" methods (case studies, small-n), the share of women exceeds their membership share in the APSA.

Another way to assess the extent to which methodological affinities play a role in the gender differences we observe is to examine the prevalence of different types of work across each of the 10 journals, and to compare this with share of female authors. Figure 10 reveals striking differences across journals in their propensity to publish particular types of scholarship: whereas AJPS and JOP publish almost no qualitative articles, $W P, C P$ and $P O P$ publish a larger share of qualitative research. 
Table 2

Gender and Collaboration, All Years

\begin{tabular}{|c|c|c|c|c|c|c|c|c|c|c|c|c|}
\hline & \multirow[b]{2}{*}{$\begin{array}{l}\text { Women among } \\
\text { Authors, } \%\end{array}$} & \multirow[b]{2}{*}{$\begin{array}{l}\text { Solo Female, } \\
\qquad \%\end{array}$} & \multirow[b]{2}{*}{$\begin{array}{l}\text { Solo Male, } \\
\quad \%\end{array}$} & \multicolumn{3}{|c|}{$\begin{array}{c}\text { Gender Profile of Multi-authored } \\
\text { Publications, } \%\end{array}$} & \multicolumn{3}{|c|}{$\begin{array}{l}\text { Authorship in Publications } \\
\text { with a Female Author, \% }\end{array}$} & \multicolumn{3}{|c|}{$\begin{array}{l}\text { Authorship in Publications } \\
\text { with a Male Author, } \%\end{array}$} \\
\hline & & & & $\begin{array}{c}\text { All } \\
\text { Women }\end{array}$ & $\begin{array}{l}\text { All } \\
\text { Men }\end{array}$ & $\begin{array}{l}\text { Cross-sex } \\
\text { Team }\end{array}$ & $\begin{array}{l}\text { Team } \\
\text { Project }\end{array}$ & $\begin{array}{l}\text { All Female } \\
\text { Teams }\end{array}$ & $\begin{array}{l}\text { Cross-sex } \\
\text { Teams }\end{array}$ & $\begin{array}{l}\text { Team } \\
\text { Project }\end{array}$ & $\begin{array}{l}\text { All Male } \\
\text { Teams }\end{array}$ & $\begin{array}{l}\text { Cross-sex } \\
\text { Teams }\end{array}$ \\
\hline & (1) & (2) & (3) & (4) & (5) & (6) & (7) & (8) & (9) & (10) & (12) & (13) \\
\hline AJPS & 18 & 6.8 & 32.7 & 2.5 & 38 & 20 & 76.7 & 8.5 & 68.3 & 63.9 & 41.9 & 22.1 \\
\hline APSR & 19 & 12.3 & 40.3 & 1.1 & 31 & 15.2 & 57.0 & 3.8 & 53.1 & 53.4 & 35.8 & 17.6 \\
\hline CP & 32 & 27 & 47.6 & 3.3 & 15 & 7.2 & 28.0 & 8.8 & 19.2 & 31.8 & 21.5 & 10.3 \\
\hline CPS & 29 & 18 & 35.7 & 3.7 & 24.1 & 18.6 & 55.3 & 9.2 & 46.2 & 54.5 & 30.7 & 23.7 \\
\hline 10 & 23 & 14.8 & 40.1 & 1.8 & 27.4 & 16 & 54.6 & 5.5 & 49.1 & 52.0 & 32.8 & 19.2 \\
\hline $\mathrm{JCR}$ & 22 & 9.1 & 29.4 & 2.9 & 34 & 24.6 & 75.1 & 7.9 & 67.2 & 66.6 & 38.6 & 28.0 \\
\hline JOP & 22 & 9.3 & 29.4 & 2.6 & 35.1 & 23.6 & 73.8 & 7.3 & 66.5 & 66.6 & 39.8 & 26.8 \\
\hline POP & 35 & 26 & 44.4 & 3.4 & 12.1 & 14.2 & 40.4 & 7.8 & 32.6 & 37.2 & 17.1 & 20.1 \\
\hline PT & 33 & 30.2 & 66.3 & 0.3 & 1 & 2.1 & 7.4 & 0.9 & 6.4 & 4.5 & 1.4 & 3.0 \\
\hline WP & 23 & 17.5 & 45.4 & 2.1 & 22.5 & 12.5 & 45.5 & 6.5 & 38.9 & 43.5 & 28.0 & 15.5 \\
\hline average & 26.5 & 17.1 & 41.1 & 2.4 & 24.0 & 15.4 & 51.4 & 6.6 & 44.8 & 47.4 & 28.8 & 18.6 \\
\hline
\end{tabular}

Note: Column 1 shows the percentage of women among all authors in each journal, while columns 2-13 take an article as the unit of analysis. Columns 2 and 3 show the percentage of all articles for each journal that emerge from a woman working alone (2) or a man working alone (3). Columns 4-6 consider the profile of authorship within multi-authored publications. Columns 2-6 should therefore sum to 100 , save rounding errors. Columns 7-9 consider the gendered origins of all publications that have at least one female author (male author for columns 10-13). Column 7 finds the share of publications with at least one female author that is a collaborative project (similarly for men in column 10). The equation used to generate column $7=($ all women + cross sex $) /($ all women $+\operatorname{cross}$ sex + solo female $)=(\operatorname{col} 4+\operatorname{col} 6) /(\operatorname{col} 4+\operatorname{col} 6+\operatorname{col} 2)$. Column 8 considers the share of all publications with a female author that emerge from all female teams, and column 9 presents the share of publications with at least one female author that emerge from cross- sex collaboration. Similarly for columns 11 and 13 for men.

\section{Figure 9}

Share of Women among All Authors in Articles by Predominant Methodology

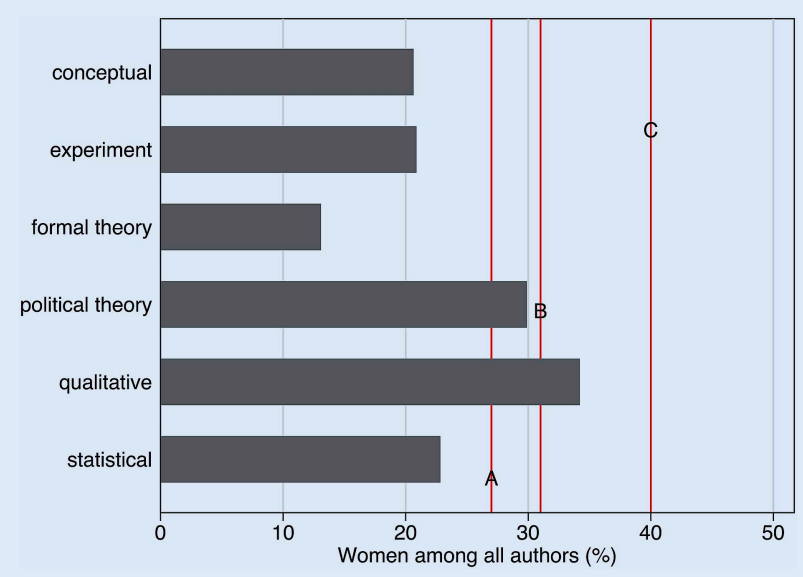

Note: The figure reports findings for all journals except Political Theory. Line A represents the share of women in the ladder faculty at the top $20 \mathrm{PhD}$-granting departments in the discipline (27\%). Line B represents the share of women among all APSA members (31\%). Line C represents the share of women among all newly minted PhDs, as reported in the NSF's survey of earned doctorates (40\%).

Linking these findings to gendered publication patterns, our findings are again similar to Breuning and Sanders (2007). We, too, observe that the journals that publish thelargest share of qualitative work map rather well onto the journals that publish higher overall shares of female authors, documented in figure 1 above. Figure 11 shows that there is a positive correlation between
Figure 10

\section{Statistical and Qualitative Methods as a Share of All Articles, 2000-2014}

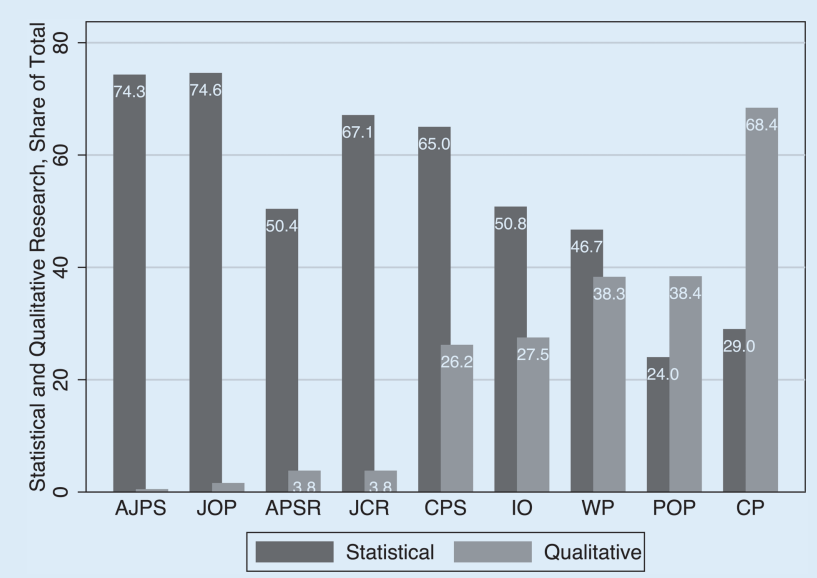

Note: Political Theory excluded.

the share of authors that are women and the share of all articles that are qualitative, and a negative correlation between female authors and statistical articles.

If a larger share of female political scientists engages in qualitative research, this would help explain why women are especially underrepresented in those journals that tilt heavily toward publishing quantitative articles. But do female political scientists in fact gravitate more toward qualitative research than their male counterparts? Although we cannot answer this 
question definitively, we can tap into APSA data to gain some initial leverage on it. One possible indicator of whether female political scientists are more prominent among qualitative researchers is membership in the APSA section devoted to qualitative and multi-method research. We obtained the section's most recent membership roster and hand-coded each of the members' gender. ${ }^{21}$ The share of women in this section $(42 \%)$ does indeed exceed the share of women in the Asso- that female political scientists may tend to pursue qualitative and multi-method research more than their male colleagues. Overall, our publications data show that very few of the top journals publish a significant share of qualitative research, but those that do tend, on average, to have more women among their author pool. Within our sample, the two journals that publish the most qualitative work (Perspectives on Politics and Comparative Politics) also publish the work of female authors

\section{Specifically, our data show that women are overrepresented among the authors of published qualitative studies, and they are underrepresented in the pages of those journals that publish very little such research.}

ciation as a whole $(31 \%)$. A second indication is the share of women among members of APSA's political methodology section, which is strongly associated with quantitative methods. Based on figures provided to us by its chair, women account for $18.4 \%$ of the section's membership, with men accounting for $81.6 \%$ of its members. ${ }^{22}$ Thus, comparing the membership profiles of these two sections against overall APSA membership share does suggest that female scholars, on average, may gravitate somewhat more toward qualitative and mixed method research than their male counterparts. ${ }^{23}$

Summing up the results of our exploration of possible connections between method, gender, and publication patterns across journals, our findings echo those of previous studies. Specifically, our data show that women are overrepresented among the authors of published qualitative studies, and they are underrepresented in the pages of those journals that publish very little such research. We have also presented some evidence in higher proportions. Conversely, the two journals that publish the fewest qualitative articles (AJPS and JOP) also publish the fewest female authors.

\section{DISCUSSION}

We have presented a series of rather sobering results for each of the three factors we considered: on the share of women in the discipline, on coauthorship, and on methods. First, our study has documented a striking and persistent gender gap in the share of female authors in 10 prominent political science journals, a gap that is especially pronounced in three of the discipline's top "generalist" journals (AJPS, JOP, and $A P S R)$. Broadly speaking there are two quite different possible explanations for why women are so underrepresented in the pages of these journals: one is that women's work is getting rejected at higher rates than men; the other is that that they are not submitting their work to these top journals in the first place.

We cannot adjudicate between these two possibilities with the (public) data available to us, but previous research provides some valuable hints. For example, Østby et al. (2013) were able to examine submission data for the Journal of Peace Research from 1983 to 2008 . They did not find evidence that papers with female authors were rejected at higher rates than men under either a single- or a double-blind editorial process. If anything, female authors may have had a slight advantage (p.9). Similarly, Breuning and Sanders (2007) acquired some limited submissions data from CPS, International Studies Quarterly, and $W P$. They, too, find that women submit at lower rates than men, but fare comparatively well in the review process, appearing in the journals at somewhat higher rates than their presence among 
all submitting authors (350).24 Overall, though, both of these studies find that women submit at lower rates than men. We think that differential rates of submission by women may well be a problem beyond the limited journals and time periods these authors were able to examine, and we are partnering with several journal editors to assemble the data needed to explore this issue. If submission rates are indeed a part of the problem, then journal editors will, with justification, respond, "We cannot accept what we don't get to review."

Our own view is that if women's self-selection bias is contributing to the patterns we have documented, this is the beginningand not the end-of the story. Such a finding would demand that we then look for the deeper structural causes, asking further: why are women not submitting their work to particular journals? Our own discipline has been at the forefront of crucial insights into the "second" face of power-that is, the idea that lack of contestation often reflects not the absence of power, but instead anticipated reactions and limited prospects for success (Gaventa 1982; Pierson 2015). A similar "second face of bias" may be at work in the patterns we observe-as female scholars rationally decline to send their work to journals that are not seen as hospitablewhether for reasons of method or more informal exclusionary signals. Over time, publication patterns can become self-enforcing, as authors begin to see it as a waste of time to submit to venues whose past publications do not include the kind of work they do. The fact that we observe, and have documented, significant variation across journals in publication rates for women suggests that we should be skeptical of explanations of the problem that attribute it to its victims.

Second, with respect to coauthorship, we observe a trend toward multi-authored publications across many of the journals in our sample. This phenomenon may be the product of "teams"-that is, emerging from research clusters or labs led by senior scholars, but often providing opportunities for more junior scholars to engage in collaborative research. To the extent that women are equally well represented in these research clusters, this can be valuable. However, our data suggest that most coauthored work in the top journals comes from teams made up of only men. What we cannot say, with the data available to us, is whether this imbalance is itself perhaps linked to other gender imbalances, for example, imbalances in which particular scholars-male or female-are landing the large research grants that are often necessary to launch these collaborative research efforts, or whether it is due to gender differences in methodological training in graduate school as senior team members perhaps look for graduate students or junior colleagues with an interest in the technical side of research, or some other factor altogether.

Beyond this, we have also suggested that coauthorship may present some dilemmas for women that are not shared by their male colleagues. More research is needed to determine whether the pattern of gender bias in the evaluation of the relative contribution of different scholars in multi-authored work-recently documented in the field of economics-is an issue in political science as well. As Sarsons has shown, in tenure decisions, female economists are penalized more than male economists for coauthoring with members of the other sex. While this could lead women to select out of publishing with men, our data shows that cross-sex collaboration produces almost half of the publications with at least one female author in these journals, which suggests that women themselves are probably not opting out of collaborations with men.

A third big takeaway from our research is that, in the prestigious journals, women are not publishing quantitative research at the same rate as men, and the top journals are publishing mostly quantitative research. Again, this raises important questions of interpretation: is it that female political scientists do do statistical research, but the top journals just do not publish it? Or-similar to Young's conjecture from 1995-are they perhaps targeting less prestigious outlets for their quantitative work? Or is there a "selection" issue in which women, on average, are drawn more toward methods or modes of scholarship that are underrepresented in these journals? The APSA membership data we have presented, though not dispositive, suggests that there may be a gendered division of methodological commitments in the discipline. If this is the case, we should not expect women to show up in journals that publish primarily quantitative work, although this does raise the possibility of de facto, unintentional barriers to gender equity, and thus the question of whether such journals might look for ways to achieve more of a balance to reflect the full range of work produced by all types of scholars.

Finally, the observation that the three journals that publish the lowest share of female authors-AJPS, JOP, and APSR-are all not only "generalist" outlets (open to all subfields and methods), but also the official flagship journals of (respectively) the Western Political Science Association, the Southern Political Science Association, and the American Political Science Association raises broader issues about the larger ecology of journal publication in political science, and about how "quality" in scholarship is defined and evaluated in our discipline. Of course, these are partly normative questions that cannot be answered with data. However, given the vital role of publication in the advancement of careers in our discipline, the patterns we have documented underscore that these questions are well worthy of future research and discussion.

\section{CONCLUSION}

The results presented here are but a first pass in understanding gendered patterns of publications in prominent political science journals; more research is clearly needed to explain the patterns we document here. In fact, we may need more than the usual evidence, since research in the STEM fields has shown that the evaluation of evidence that points to gender bias is itself genderbiased in important ways (with men more apt than women to view such research as "less meritorious"-see Handley et al. 2015). In the meantime, however, what we know for sure is that the underrepresentation of women in the Association's top journals that we have documented is a problem for women in the profession because of the indisputable importance attached to publications at all stages, from hiring, to tenure, to promotion decisions. More and more women are seeking careers in our field-closing in on half of all PhDs-making equal access to the field's top journals extremely important, indeed, urgent. Publications are, in the words of the Chair of APSA's Committee on the Status of Women in the Profession, Frances Rosenbluth, "the coin of our realm." Journal editors are important gatekeepers whose actions-and inactionsare enormously consequential in establishing who advances through the pipeline and whose work sets the agenda for the discipline as a whole. 
Moving forward, then, we recommend additional data collection-encompassing more of the field's journals and involving more fine-grained coding of some of our key variables, for example to capture mixed methods research. As already noted, we are working with a number of journal editors to collect submission data and analyze these for their gender and methodological content. We invite other journal editors to participate in this project, whose results can form the empirical basis for a broader discussion within the discipline.

For the centennial edition of The American Political Science Review, editor Lee Sigelman organized a full issue devoted to the theme of "the evolution of political science" (2006). The idea was to examine trends in the kinds of articles that appeared in the Review as a window on the evolution of the discipline over the previous century. One of these articles, by Sue Tolleson-Rinehart and Susan J. Carroll, examined the way in which the role of women in the discipline had changed over time. Their conclusion, summarized in the title and borrowing a phrase from Judith Shklar, APSA's first female president, ${ }^{25}$ was that although progress had certainly been made since women entered the discipline, the situation was still "far from ideal." Ten years on-now against the backdrop of a growing number of women who are seeking to make a career in political science and the stagnation of publication rates in many of the discipline's top journals-we are inclined to render the somewhat less sanguine verdict: if anything, we seem to be even further from ideal.

\section{ACKNOWLEDGMENTS}

We would like to thank Elissa Berwick and Kelly Pasolli for their assistance in the research reported here, and Michel Weaver for his expert knowledge of web-scraping techniques. A great many friends and colleagues have provided valuable suggestions; we thank Karen Alter, Kristin Bakke, Mona Morgan Collins, Frank Cullen, Bonnie Fisher, Peter Hall, Nancy Hirschmann, Mala Htun, Ben Lauderdale, Erin Leahey, Thomas Leeper, Matt Levendusky, Julie Lynch, Jane Mansbridge, Tali Mendelberg, Marc Meredith, Avia Pasternak, Jess Stanton, Barbara Walter, Elisabeth Wood, and the participants in the University of Chicago event on "diversity and inclusion," particularly the conveners Cathy Cohen and Patchen Markell. We are also grateful to Marijke Breuning and John Ishiyama, who have facilitated our work on this project from its inception. And finally, a special thanks to Frances Rosenbluth, who convened the APSA panel on which these results were first presented, and who has been a strong supporter of the project.

\section{NOTES}

1. A recent Nature article offered a sobering overview of limited progress across a range of measures (Urry 2015).

2. These same data have also been used to provide evidence of gendered syllabi in international relations (http://duckofminerva.com/2015/o8/new-evidenceon-gender-bias-in-ir-syllabi.html). A subsequent, much larger study of citation patterns across a wider range of disciplines (based on an analysis of 1.6 million articles published between 1950 and 2015) shows that the gap between male and female patterns of self-citation grew significantly since 1950. ("Men who admire their own work" Inside Higher Ed, August 25, 2015).

3. Karen Alter, Jean Clipperton, Emily Schraudenbach, Vijay Siddappa Murganoor, Laura Rozier, "Wikipedia, Gender and Status in American Political Science: Who determines whether a scholar is noteworthy?" In a similar vein, see Stegmaier Palmer, and van Assendelft on the representation of women on the editoria boards of political science journals (2011).

4. http://web.apsanet.org/cswp/data/

5. See, most recently, Evans and Moulder (2011), and also Breuning and Sanders (2007), in particular, whose analysis of methodology in the journals is very close to our own. While our study covers a longer time frame (15 volume years, against their six) and a somewhat wider range of journals (10, rather than eight), their study also provides preliminary evidence of submission rates. We will return to this important issue below.

6. Young's study, like many others, codes on articles rather than authors-that is, the findings are rendered in terms of the share of articles with at least one female author (see also Evans and Moulder 2011, who use this measure as well). By contrast, we present our results in terms of female authors as a share of all authors. We prefer this measure because we are interested in promotion and career advancement, and of course every author who contributes to a particular article lists the publication on his/her CV. In other words, for Young an article coauthored by one woman and one man is equivalent to one coauthored by one woman and four men, whereas for us, these two articles combined would show up on the publication records of seven scholarsfive men and two women. Taking "share of articles with at least one female author" as the measure produces a more sanguine picture (e.g., Evans and Moulder 2011), until one sets this figure against the parallel "share of articles with at least one male author" (which produces a figure far above the share of men in the profession).

7. http://www.nsf.gov/statistics/srvydoctorates/ An alternative NSF measure (total $\mathrm{PhDs}$ awarded in political science and public administration, combined) produces an even higher figure of around $45 \%$ (and as high as $47 \%$ in 2008 ). See http://www.nsf.gov/statistics/doctorates/

8. For example, Political Theory does not show up as a "top" journal in general rankings, but it is widely recognized as an especially high-prestige outlet for that subfield. Comparative Politics lags behind the other journals in some of the rankings, but was included because it has a reputation for publishing qualitative-as well as quantitative-work.

9. The research methods used in each article include: formal theory, statistical, qualitative, experiment, normative, conceptual.

10. Although gender is socially constructed, the dichotomy has been historically important and is therefore useful for quantitative analysis.

11. http://genderize.io/. We also compared the hand-coded results to the guessed genders, finding 98\% accuracy. The "genderize" algorithm lists the probability that its guess is "correct", and where this was lower than 1, we hand-checked the author gender against institutional web sites.

12. Source: APSA "P-WAM2o: Pipeline for Women and Minorities," based on selfreported statistics from the 20 largest $\mathrm{PhD}$-granting institutions for political science (UCLA and UCSD not reporting). These data are available at http:// web.apsanet.org/cswp/data/.

13. The share of women on the faculties of what the US News and World Report considers the "top ten" departments is similar to that of the largest $20 \mathrm{PhD}$ granting departments, at 26\% in 2015 (APSA P-WAM20).

14. See http://www.mpsanet.org/AJPS/tabid/18o/Default.aspx for AJPS (the journal of the Midwest Political Science Association) and http://spsa.net/about-spsa/ journal-of-politics/ for JOP (the journal of the Southern Political Science Association). Other regional associations also have their own journals-for example, the Northeastern Political Science Association sponsors Polity, the Western Political Science Association sponsors Political Research Quarterly, and the New England Political Science Association sponsors the New England Journal of Political Science. However, none of these other journals appeared consistently high enough in the various rankings to be included in this particular study.

15. These figures mimic findings on the gendered patterns of authorship in the Journal of Peace Research over the years 1983-2008. Østby et al. (2013) report that in that time period, $59 \%$ of articles featured a man working alone; $18 \%$ of articles emerged from all-male teams; a woman worked alone in $10 \% ; 12 \%$ of publications were cross-gender teams; and only $1 \%$ were all-female teams.

16. See also Evans and Moulder (2011), whose study of four political science journalsincluding three of those in our sample-came to identical conclusions $(2011,796)$

17. Some of these same issues have reappeared in recent debates (see e.g., Isaac 2015).

18. A previous study by Breuning et al. (2005) reaches the same conclusion, based on data from a smaller set of three international relations journals.

19. They also find that when women do publish in these journals, their articles are mostly quantitative $(2011,796)$. This finding comports with our data, which shows that three of the four journals considered in their study publish almost no qualitative work.

20. We are currently working with several journal editors to develop a uniformbut also more differentiated-coding scheme that can also better accommodate multi-method research.

21. We were able to identify the gender of all but 13 (2\%) of the 631 section members. In some cases, this involved a web search.

22. These figures are based on a combination of machine- and hand-coding, with the machine-coding by https://civic.mit.edu/open-gender-tracker. Out of a tota of 575 members, 104 were women, 460 were men, and 11 could not be assigned with certainty. We are grateful to Jeff Lewis for providing these figures.

23. Perhaps a third indication is the share of women who are participants in the Political Methodology conference. In 2014, 26.4\% of attendees were female (the highest number since the annual conference began in 1984; the share of female participants is typically closer to 20\%) (Unkovik, Sen, and Quinn 2016 : table S2; see also Shames and Wise 2017). 
24. At World Politics, from 1999-2004, 23.2\% of submissions were by femal authors, while $26 \%$ of authors published in that timeframe were women. $C P S$ and $I S Q$ provided three years of data, and for these journals as well, it appears that female authors publish in somewhat higher share than their submission rates (which were $21 \%$ for CPS and $15.4 \%$ for ISQ) (Breuning and Sanders 2007: 350).

25. Elected in 1989 .

\section{REFEREN CES}

APSA. 2005. Women's Advancement in Political Science: A Report of the APSA Workshop on the Advancement of Women in Academic Political Science in the United States. Washington DC: American Political Science Association.

. 2016. "P-WAM20: Pipeline for Women and Minorities in the 20 Largest Departments - Data for Faculty and Students." Washington, DC: American Political Science Association.

Breuning, Marijke, Joseph Bredehoft and Eugene Walton. 2005. "Promise and Performance: An Evaluation of Journals in International Relations." Internationa Studies Perspectives 6 (4): 447-61.

Breuning, Marijke and Kathryn Sanders. 2007. "Gender and Journal Authorship in Eight Prestigious Political Science Journals.” PS: Political Science \& Politics $40(2): 347-51$

Evans, Heather K. and A. Moulder. 2011. "Reflecting on a Decade of Women's Publications in Four Top Political Science Journals.” PS: Political Science $\mathcal{E}$ Politics 44 (4): 793-98.

Fisher, Bonnie S., Craig T. Cobane, Thomas M. Vander Ven, and Francis T. Cullen. 1998. "How Many Authors Does It Take to Publish an Article? Trends and Patterns in Political Science." PS: Political Science \& Politics 34 (4): 847-56.

Gaventa, John. 1982. Power and Powerlessness: Quiescence and Rebellion in an Appalachian Valley. University of Illinois Press.

Giles, Micheal W. and James C. Garand. 2007. "Ranking Political Science Journals: Reputational and Citational Approaches." PS: Political Science \& Politics 40 (4): 741-51.

Handley, Ian M., Elizabeth R. Brown, Corinne A. Moss-Racusin and Jessi L. Smith. 2015. "Quality of Evidence Revealing Subtle Gender Biases in Science is in the Eye of the Beholder." Proceedings of the National Academy of Sciences 112 (43): 13201-13206.

Isaac, Jeffrey C. 2015. "For a More Public Political Science." Perspectives on Politics 13 (2): 269-83.
Karpowitz, Christopher F. and Tali Mendelberg. 2014. The Silent Sex: Gender, Deliberation, and Institutions. Princeton, NJ: Princeton University Press.

MacNell, L., A. Driscoll, A. N. Hunt. 2015. "What's In A Name: Exposing Gender Bias In Student Ratings Of Teaching." Innovative Higher Education 40 (4): 291-303.

Maliniak, Daniel, Ryan Powers and Barbara Walter. 2013. "The Gender Citation Gap in International Relations.” International Organization 67 (4): 889-922.

Østby, Gudrun, Håvard Strand, Ragnhild Nordås, and Nils Petter Gleditsch. 2013. "Gender Gap or Gender Bias in Peace Research? Publication Patterns and Citation Rates for Journal of Peace Research, 1983-2008." International Studies Perspectives 14 (4): 493-506.

Pierson, Paul. 2015. "Power and Path Dependence." In Advances in ComparativeHistorical Analysis, eds. James Mahoney and Kathleen Thelen, 123-45. New York: Cambridge University Press.

Sarsons, Heather. 2015. “Gender Differences in Recognition for Group Work." Harvard Economics Department Working Paper. December 3, 2015.

Shames, Shauna and Tess Wise. 2017. "Gender Diversity and Methods in Political Science: A Theory of Selection and Survival Biases." forthcoming PS: Political Science \& Politics.

Stegmaier, Mary, Barbara Palmer, and Laura van Assendelft. 2011. "Getting on the Board: the Presence of Women in Political Science Journal Editorial Positions." PS: Political Science \& Politics 44 (4): 799-804.

Tolleson-Rinehart, Sue and Susan J. Carroll. 20o6. "Far From Ideal:" The Gender Politics of Political Science." American Political Science Review 100 (4): 507-13

Trix, Frances and Carolyn Psenka. 2003. Exploring the Color of Glass: Letters of Recommendation for Female and Male Medical Faculty. Discourse and Society 14 (2): 191-220.

Unkovic, Cait, Maya Sen, and Kevin M. Quinn. 2016. "Does Encouragement Matter in Improving Gender Imbalances in Technical Fields? Evidence from a Randomized Controlled Trial." PLoS ONE 11 (4): 1-15.

Urry, Meg. 2015. "Science and Gender: Scientists Must Work Harder on Equality." Nature December 21. http://www.nature.com/news/science-and-genderscientists-must-work-harder-on-equality-1.19064?WT.mc_id=FBK_NA_1512 NEWSCOMMENTEQUALITY_PORTFOLIO.

Wennerås, Christine and Agnes Wold. 1997. "Nepotism and Sexism in Peer-Review." Nature 387: 341-43

Young, Cheryl D. 1995. "An Assessment of Articles Published by Women in 15 Top Political Science Journals." PS: Political Science \& Politics 28 (3): 525-33. 
The Profession: Publication Patterns in Political Science

\section{APPENDIX: Collaboration in Political Science Journals Over Time}

Multiple Authored

\begin{tabular}{|c|c|c|c|c|c|c|}
\hline Journal & & Percent Multiple Authored & Percent Two Authors & Percent Three Authors & Percent Four or More & n \\
\hline \multicolumn{7}{|l|}{ ALL } \\
\hline & 1999-2009 & 40.8 & 28.5 & 9.6 & 2.7 & 3577 \\
\hline & 2010-2015 & 50.2 & 33.1 & 11.5 & 5.5 & 2166 \\
\hline \multicolumn{7}{|l|}{ AJPS * } \\
\hline & 1950-1959 & 3.8 & 50.0 & 0.0 & 50.0 & 53 \\
\hline & 1960-1969 & 15.4 & 85.3 & 14.7 & 0.0 & 221 \\
\hline & 1970-1979 & 28.1 & 80.6 & 13.9 & 5.6 & 384 \\
\hline & 1980-1989 & 44.4 & 75.4 & 20.8 & 3.8 & 412 \\
\hline & 1990-1996 & 51.1 & 66.7 & 25.0 & 8.3 & 282 \\
\hline \multirow[t]{2}{*}{ AJPS } & 1999-2009 & 57.3 & 39.6 & 12.4 & 5.3 & 571 \\
\hline & $2010-2015$ & 66.1 & 39.8 & 16.8 & 9.6 & 322 \\
\hline \multicolumn{7}{|l|}{ APSR* $^{*}$} \\
\hline & 1950-1959 & 8.5 & 81.8 & 15.2 & 3.0 & 387 \\
\hline & 1960-1969 & 18.7 & 78.4 & 14.9 & 6.8 & 396 \\
\hline & 1970-1979 & 26.3 & 80.8 & 14.4 & 4.8 & 475 \\
\hline & 1980-1989 & 43.6 & 73.7 & 21.2 & 5.1 & 451 \\
\hline & 1990-1996 & 45.3 & 72.9 & 20.4 & 6.9 & 318 \\
\hline \multirow[t]{2}{*}{ APSR } & 1999-2009 & 43.3 & 26.9 & 13.6 & 2.9 & 383 \\
\hline & $2010-2015$ & 54.2 & 37.4 & 13.2 & 3.5 & 227 \\
\hline \multicolumn{7}{|l|}{$\mathrm{CP}$} \\
\hline & 1999-2009 & 19.5 & 18.0 & 1.5 & 0.0 & 200 \\
\hline & 2010-2015 & 36.4 & 29.9 & 5.6 & 0.9 & 107 \\
\hline \multicolumn{7}{|l|}{ CPS } \\
\hline & 1999-2009 & 41.0 & 31.9 & 7.6 & 1.6 & 502 \\
\hline & $2010-2015$ & 55.6 & 39.2 & 13.5 & 2.8 & 288 \\
\hline \multicolumn{7}{|l|}{10} \\
\hline & 1999-2009 & 41.0 & 30.4 & 9.2 & 1.4 & 217 \\
\hline & 2010-2015 & 53.0 & 38.3 & 11.3 & 3.5 & 115 \\
\hline \multicolumn{7}{|l|}{ JCR } \\
\hline & 1999-2009 & 57.6 & 42.4 & 12.0 & 3.1 & 191 \\
\hline & 2010-2015 & 66.0 & 43.4 & 17.6 & 5.0 & 159 \\
\hline \multicolumn{7}{|l|}{ JOP* } \\
\hline & 1950-1959 & 4.6 & 100 & 0.0 & 0.0 & 237 \\
\hline & 1960-1969 & 12.1 & 83.3 & 13.9 & 2.8 & 298 \\
\hline & 1970-1979 & 22.1 & 80.6 & 16.1 & 3.2 & 420 \\
\hline & 1980-1989 & 36.2 & 80.5 & 17.8 & 1.7 & 481 \\
\hline & 1990-1996 & 51.3 & 78.4 & 18.0 & 3.5 & 335 \\
\hline \multirow[t]{2}{*}{ JOP } & 1999-2009 & 59.6 & 38.4 & 17.5 & 3.7 & 617 \\
\hline & $2010-2015$ & 63.9 & 43.2 & 13.1 & 7.6 & 396 \\
\hline \multicolumn{7}{|l|}{ POP } \\
\hline & 1999-2009 & 29.9 & 20.6 & 5.2 & 4.1 & 291 \\
\hline & 2010-2015 & 29.5 & 13.9 & 7.6 & 7.9 & 302 \\
\hline
\end{tabular}




\section{APPENDIX (Continued)}

Multiple Authored

\begin{tabular}{|c|c|c|c|c|c|c|}
\hline Journal & & Percent Multiple Authored & Percent Two Authors & Percent Three Authors & Percent Four or More & $\mathbf{n}$ \\
\hline \multicolumn{7}{|l|}{ PT } \\
\hline & 1999-2009 & 2.4 & 2.4 & 0.0 & 0.0 & 451 \\
\hline & $2010-2015$ & 6.1 & 4.9 & 0.6 & 0.6 & 164 \\
\hline \multicolumn{7}{|l|}{ WP } \\
\hline & 1999-2009 & 35.7 & 26.0 & 7.8 & 1.9 & 154 \\
\hline & $2010-2015$ & 39.5 & 29.1 & 4.7 & 5.8 & 86 \\
\hline
\end{tabular}

*Years marked under the asterisk reflect data collected by Fisher et al. (1998). 